\title{
Dynamic Distribution of Berth-Quay Crane Based on Ship’s Priority
}

\author{
Zhang Yutao ${ }^{1,}$, $*$, Zhao Gang ${ }^{1, b}$ \\ ${ }^{1}$ College of Transport \& Communications, Shanghai Maritime University, Shanghai, China \\ ${ }^{2}$ College of Transport \& Communications, Shanghai Maritime University, Shanghai, China \\ a1620065818@qq.com, b gangzhao@shmtu.edu.cn \\ *corresponding author
}

Keywords: Continuous berth; The preference location; Priority; Dynamic scheduling

\begin{abstract}
As an important strategic resource, berth and quay crane are relatively scarce. If reasonable allocation of berth and quay crane can be made with full use, then it can greatly improve the efficiency of port's operations. The first objective of most of issues in the study is to minimize the total time of vessels in port. There is no consideration of loss behind the planned period, which has caused the waste of resources. To solve the above problems, based on the continuity of berth, the location preference and the priority of ship, it can be assumed that the quay crane can be dynamically scheduled during the operation to build the dynamic model of the berth and quay crane. The model mainly ensures that the ship has the least amount of unloading after the time that behind the planned departure. This model is dealt with by CPLEX, and the validity of the dynamic scheduling model of the berth and quay crane is confirmed.
\end{abstract}

\section{Introduction}

With the continuous development of science, technology and the global economy, the shipping market began to rebound. Port operations are increasingly busy and the competition that between ports becoming fiercer. How to make better use of the port scarce--berth and quay crane, and make them become more reasonable have been a hot topic. The problem about berth allocation is an important operation problem of container terminals. According to the form of berth arrangement, the wharf can be divided into continuous wharf and discrete wharf. This problem is mainly used to determine the berthing position and operating time of the ship. The problem of allocation about quay crane is mainly used to ensure the allocation of the designated ship and the number of quay crane to ensure that the ship can complete the amount of work in specified time.

When studying berth and quay crane distribution, most scholars only guarantee that the ship has the least total time in port. Put it another way, assume that each ship has its planned departure time and the port only needs to ensure that each vessel can be able to complete its mission before the planned departure time. Although this will increase the total time of the ship in port, it can ensure that the fee is the least after the planning period. For example, Meisel and other considerations affecting the operating efficiency of berthing location across the bridge, optimization model are to minimize the cost of ship service, and are solved by heuristic algorithm ${ }^{[1]}$. Wang June etc according to the ship's berthing time, the working position, and the correlation of each parameter, establish the mathematic model with the goal of minimizing the ship's time in port, and the genetic algorithm is used to solve the problem ${ }^{[2]}$. As for Chen Shelian in the case of dynamic distribution of the quay crane, the model of minimizing the ship's time in port is established, and the ship location is planned by the brother-son method, which makes the quay crane not cross work ${ }^{[3]}$. Liang Chengji and so on, according to ship operating time, wait time and delay time minimum, established an optimization model, based on the quay crane mobile using a hybrid genetic algorithm to solve [4]. Imai et al reach berth for dynamic allocation of the ship, in order to minimize waiting time and the operating time of each of the target ship, designed heuristic ${ }^{[5]}$. Han Jun put forward the berth and bridge with the minimum time for the target ship in the port crane coordination scheduling optimization method, and a method is given to solve the immune genetic algorithm based on mode 
$\mathrm{l}^{[6]}$. In studying the problem, the above scholars have aimed at minimizing the time spent in port, without taking into account the delay in loading and unloading of ships after they have planned to leave terminal. When Liang Chengji, Xia Sangju, Lu Bo propose dynamic scheduling of ships in berths where continuity exists, and minimize the residual amount of the ship after the earliest departure time period ${ }^{[7]}$. In the case of joint dispatching of berth and quay crane of Peng Lijiao, Han Xiaolong, an integer programming model is established, which aims at minimizing the amount of delayed completion task, and deviating from best berthing position and the penalty cost of quay crane's movement ${ }^{[8]}$. Although the author considers the delay fee after the planning period, the priority of the ship is not considered. In view of the ship's priority, Zhang Di, strict south-south the ship service priority as the influence factor, establishes the optimization model which aims at minimizing the ship waiting time, working time and delay time ${ }^{[9]}$. Lussay, and Han Xiaolong determine the ship's priority by the amount of the ship's operation, and take priority as the influence factor of the objective function of berth allocation ${ }^{[10]}$. Imai et al. considered the priority of ship services, modified the existing model, and used genetic algorithms to solve the problem ${ }^{[11]}$. In short, for most scholars in the study of the problem, there is no delay in considering the fee after the planning period and ship's priority.

\section{The description of problem}

If the efficiency of each shore bridge is 50TEU/h, Plan 1, if assign to the ship that has 1000TEU container and 4 shore bridges and plans to take 10 hours to complete the work, the ship only needs 5 hours to complete the task. Plan 2, in the first 3 hours allocated to the ship 4 shore bridges, after 4 hours allocated to the ship 2 shore bridges, so the remaining shore bridges can be allocated to other ships, though 7 hours needed to complete the workload. The ship can also complete the task before the planning period without causing any loss. The main idea of this paper is to make full use of the period of planning departure.

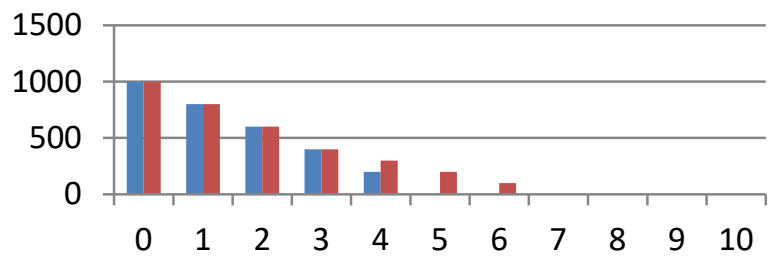

Fig 1 Scenario Comparison Chart

\section{Model building}

To solve this problem, this paper established a dynamic model. For traditional model, they are just make sure ship security between each other that in space and time will not conflict.

\subsection{Basic assumptions}

On the basis of the traditional model of the berth allocation, this paper stipulates that the number of quay cranes allocated to the ship can change during the work and makes the following assumptions;

(1) The speed of loading and unloading of each quay crane is 50TEU/h;

(2) Does not consider the moving range of the quay crane and the time of the quay crane that need to move;

(3) Does not take into account the operating cost of the quay crane;

(4) The ship during the operation must ensure that the quay crane for its services, but the distribution of the number of bridges cannot exceed the maximum operating road of the ship;

(5) Each vessel has its preferred position; 


\subsection{Input variables}

$T$ indicates a set of time;

$t$ indicates time, $t \in T$

$I$ indicates a collection of ships;

$i$ indicates a ship, $i \in I$

$P T_{i}$ indicates the time when the ship i plan to depart from the port;

$p_{i}$ indicates the preferred position of ship i;

$a_{i}$ indicates the arrival time of the ship $\mathrm{i}$;

$L$ indicates the length of the shore line;

$l_{i}$ indicates that the ship's length and the safe distance;

$Q$ indicates the number of available quay cranes;

$V$ indicates that the quay crane loading and unloading speed is 50TEU/h;

$A$ indicates the penalty factor for ship i working after the planning period;

$B$ the penalty coefficient due to the distance between the preference position and berthing position;

$C$ indicates the cost due to the mobile of the quay cranes;

$E_{i}$ indicates the ship i need to unload the number of the containers;

$m_{i}$ indicates the priority of ship i;

$x_{i}$ indicates the position of the ship i docking;

$y_{i}$ indicates the berthing time of the ship i;

$n_{i t}$ indicates the number of quay cranes assigned to the ship $\mathrm{i}$ at the moment $\mathrm{t}$;

$R_{i t}$ indicates the amount of unloaded containers at time t of ship i;

$D L_{i}$ indicates the distance from the docking position of ship i to the ship's preferred position;

$c_{i t}$ indicates the number of change of quay cranes assigned to ship i at time $t$ compared to the previous one;

$\sigma_{i j}$ if the ship i docked on the left side of the ship $\mathrm{j}$ so the value is 1 , otherwise is 0 ;

$\beta_{\text {it }}$ it means that there are quay cranes assign to the ship $\mathrm{i}$ at time $\mathrm{t}$ and the value is 1 , otherwise is 0 ;

\subsection{Mathematical model}

$$
\begin{aligned}
& \min f=\sum_{1}^{I}\left(A \cdot \sum_{P T_{i}}^{T} R_{i t}+B \cdot D L_{\mathrm{i}}+\mathrm{C} \cdot \sum_{1}^{T} c_{i t}\right) \cdot \mathrm{m}_{i} \\
& \text { s.t } \\
& D L_{i}=\left|x_{i}-p_{i}\right|, i \in I \\
& x_{i}+l_{i} \leq L, i \in I \\
& x_{i}+l_{\mathrm{i}} \leq x_{j}+M\left(1-\sigma_{i j}\right), i, j \in I, i \neq j \\
& \beta_{i t}+\beta_{j t} \leq 1+\sigma_{i j}+\sigma_{j i}, i, \quad j \in I \text { andi } \neq j, t \in T \\
& \frac{R_{i t}}{E_{i}}+\beta_{i t-1}-1 \leq \beta_{i t} \leq \beta_{i t-1} \quad, \mathrm{i} \in \mathrm{I}, \mathrm{t} \geq 1 \\
& R_{i t}=0, i \in I, t<a_{i} \\
& R_{i a_{i}}=E_{i}, i \in I \\
& R_{i t} \geq R_{i t-1}-n_{i t-1} V, i \in I, t>a_{i}
\end{aligned}
$$




$$
\begin{aligned}
& R_{i t} \geq 0, i \in I, \mathrm{t} \in T \\
& R_{i N b T} \leq 0, i \in I \\
& \beta_{i t} \leq n_{i t} \leq \beta_{i t} \mathrm{D}_{i}, \mathrm{i} \in \mathrm{I}, \mathrm{t} \in \mathrm{T} \\
& \sum_{i}^{I} n_{i t} \leq Q, i \in I, t \in T \\
& m_{i}=\frac{E_{i}}{\lambda}, \mathrm{i} \in I \\
& \mathrm{c}_{i t} \geq n_{i t}-n_{i t-1}, \mathrm{t} \geq 1 \\
& \sigma_{i j} \in\{0,1\}, i, j \in I \\
& \beta_{\mathrm{it}} \in\{0,1\}, i \in I, t \in T
\end{aligned}
$$

The objective function (1) ensures that, based on the priority of the ship the sum of the cost of the loss, the deviation of position and the moving cost of the quay crane is minimized. Equation (2) means the deviation of position; equation (3) ensures that the ship will not exceed the shore line; equation (4) ensures the two berthing position do not conflict; equation (5) avoid two ships at the same time berthing in the same position; equation (6) ensures continuous work of ship; The equation (7) (8) (9) (10) stipulate the relationship of the $R_{i t}$ and $t$. equation (11) guarantees the ship to complete the loading and unloading before departure; equation (12) ensures that the number of quay cranes that assigned to the ship will not exceed the maximum operating road of the ship; equation (13) ensures that the number of quay cranes working at the same time will not exceed the total number of quay cranes; equation (14) defines the priority of ship; Equation (15) defines the number of change of quay cranes; Equation (16) (17) define the values of the $\sigma_{i j}, \beta_{i t}$.

\section{Experimental calculation example}

In order to study the validity of the above model, the ship information of a port is assumed and solved by CPLEX.

\subsection{Input the data}

Suppose the length of a port is $1300 \mathrm{~m}$, the available quay cranes are 15 and the working efficiency of each quay crane is $50 \mathrm{TEU} / \mathrm{h}$, the planning period is $48 \mathrm{~h}$ and the time unit is 1 hour. Other data are shown in Table 1 . A takes $0, \mathrm{~B}$ takes 25, C takes 5, $\lambda$ takes 2500.

Table 1. Original data of ship.

\begin{tabular}{ccccccc}
\hline $\begin{array}{c}\text { The number } \\
\text { of ship i }\end{array}$ & $\begin{array}{c}\text { Length of } \\
\text { ship } l_{i}\end{array}$ & $\begin{array}{c}\text { Ship } \\
\text { unloading } \\
\text { volume } E_{i}\end{array}$ & $\begin{array}{c}\text { Arrival time } \\
\text { of ship } a_{i}\end{array}$ & $\begin{array}{c}\text { The planning } \\
\text { departure } \\
\text { time } P T_{i}\end{array}$ & $\begin{array}{c}\text { The } \\
\text { preference } \\
\text { position of } \\
\text { the ship } P_{i}\end{array}$ & $\begin{array}{c}\text { The ship's } \\
\text { maximum } \\
\text { operating } \\
\text { road. } D_{i}\end{array}$ \\
\hline 1 & 160 & 1100 & 1 & 10 & 0 & 3 \\
2 & 249 & 2500 & 2 & 16 & 800 & 4 \\
3 & 267 & 1987 & 8 & 23 & 200 & 3 \\
4 & 240 & 2100 & 10 & 25 & 600 & 3 \\
5 & 300 & 2600 & 12 & 23 & 300 & 5 \\
6 & 122 & 790 & 15 & 24 & 500 & 2 \\
7 & 160 & 1500 & 16 & 28 & 100 & 3 \\
\hline
\end{tabular}




\subsection{The solution of model}

This paper uses CPLEX to solve the model. For ship 1, it dockes at $300 \mathrm{~m}$, and from the 1 th to the 9th needs 3 quay cranes; For ship 2, it dockes at $840 \mathrm{~m}$, and from the 2th to 14th, assign 4 quay cranes to it. Because at 14th the remaining capacity is 100 TEU and the ship plan to finish its work at 16th, in addition to this paper, taking an hour as the unit of time, if assign 4 quay cranes to ship 2, also needs 1 another hour to finish the work that cause the waste of resources, so from 14th to 15th only assign 2 quay cranes ; Ship 3, dockes at 33m,from 8th to 19th assign 3 quay cranes to it, from 19th to 22th assign 2 quay cranes, because in this period, if continued to assign 1 quay crane, the ship 6 will spend more time completing the task, which exceeds the planning time, from 22th to 23th assign 3 quay cranes, because at this time ship 5 reduce 1 quay crane; Ship 4, dockes at 600m, working time is from 10th to 24th, the number of quay crane is 3; Ship 5, stops at $300 \mathrm{~m}$, between 12th and 22th assign 5 quay cranes, from 22th to 23th assign 4 quay cranes, because the ship need to uninstall $100 \mathrm{TEU}$ at 22th and the planning departure time is 23th, the distribution of 4 quay cranes just can finish work at the planned departure time. Ship 6, stops at $1089 \mathrm{~m}$, needs 2 quay cranes during the 15th to 16th, in order to ensure that do not exceed the total number of quay cranes, so during the 16th to the 19th assign 1 quay crane, due to the number of the quay crane of the ship 3, 5 change, so from the 19th to 25th assign 2 sets to ship 6; Ship 7, dockes at 840m, from 16th to 26th assign 3 quay cranes to it.

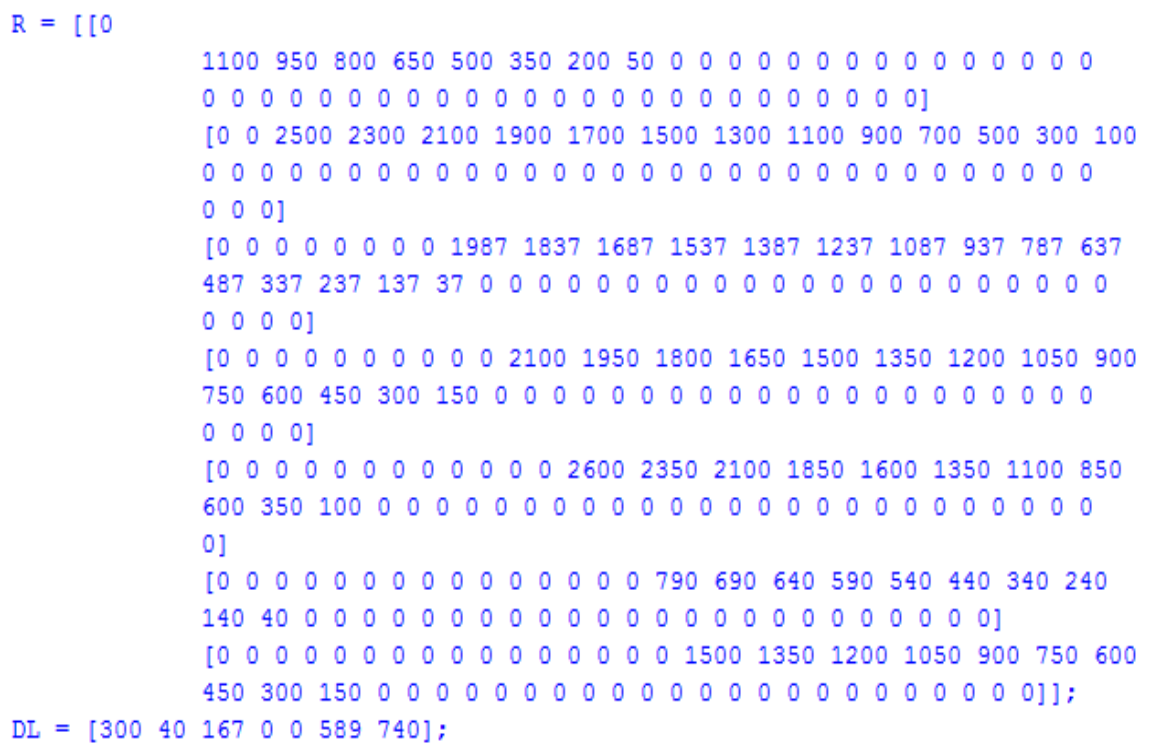

Fig 2. The solution by CPLEX

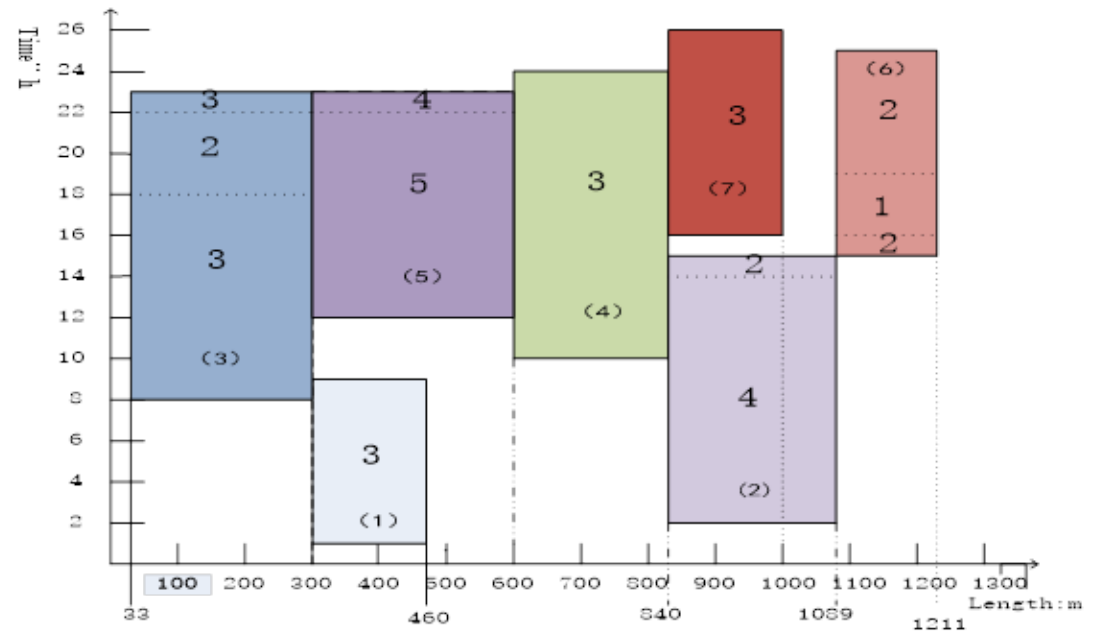

Fig 3. Berth- Quay Crane distribution diagram 


\section{Conclusions}

On the basis of considering the ship's priority, the position of ship's preference and the cost of quay crane dispatching, the dynamic model which can reduce the loss of ship in port to some extent is established. The validity of the model is also proved by the algorithm case. But some of the parameters are just the author's assumptions, the specific value needs further consideration.

\section{References}

[1] Meisel F, Bierwirth C. Heuristics for the integration of crane productivity in the berth allocation problem[J]. Transportation Research Part E,2009,45(1):196-209.

[2] Wang June, Li Chuoyong. Research on optimization of dynamic berth allocation problem based on genetic algorithm [J]. China water Transport. 2011.11 (1).

[3] The Zhi should be. An algorithm for continuous berth allocation with dynamic distribution of bridge crane [J]. Computer Application-2012, 32 (5).

[4] Liang Chengji, Huang Youfang, Yang Yang. A quay crane dynamic scheduling problem by hybrid evolutionary algorithm for berth allocation planning [J] Computers and Industrial Engineering, 2009, 56(3).

[5] Imai A., Nishimura E., Papadimitriou S.. Thedynamic berth allocation problem for a container Port [J]. Transportation Research Part B, 2001, 35(4):401-417.

[6] Han Jun, Sun Xiaona, Shihong. Optimization of container terminal berth and Shore Bridge Coordination dispatch [J]. Journal of Dalian Maritime University, 2008, 34 (2): 117-121.

[7] Liang, Chassan, the Bohai Sea. Dynamic configuration of container port continuous berth and Shore Bridge [J]. Journal of Chongqing Jiaotong University (Natural Science Edition). 2016, 35 (5).

[8] Peng Li, Han Xiaolong. Joint optimization of berth allocation under continuous berth and dynamic dispatching of Shore Bridge [J]. Water Transport Engineering-2013, 4 (478).

[9] Zhang Di, Yan nannan. Berth-shore Bridge allocation considering ship service priority [J]. Modern computer. 2015, 14 (011).

[10] Lussay, Han Xiaolong. Berth and Shore bridge coupling optimization based on ship priority [J]. Henan Science. 2014,32 (4).

[11] Imai A., Nishimura E., Papadimitriou S. Berth allocation with service priority [J]. Transportation Research Part B,2003,37(5):437-457. 